Ocean Dynamics manuscript No.

(will be inserted by the editor)

\title{
1 Formation events of shoreline sand waves on a gravel
}

\section{2 beach}

3 Jaime Arriaga · Albert Falqués · Francesca

4 Ribas - Eddie Crews

6 Received: date / Accepted: date

7 Abstract Kilometric-scale shoreline sand waves (KSSW) have been observed in

8 the north-east flank of the Dungeness Cuspate Foreland (southeastern coast of

J. Arriaga

Physics Department, Universitat Politècnica de Catalunya, Campus Diagonal Nord, C. Jordi

Girona 1-3, 08034 Barcelona, Catalonia, Spain

Tel.: +34-934017761

Fax: +34-934016090

E-mail: jaime.alonso.arriaga@upc.edu

A. Falqués

Physics Department, Universitat Politècnica de Catalunya, Barcelona, Spain

E-mail: albert.falques@upc.edu

F. Ribas

Physics Department, Universitat Politècnica de Catalunya, Barcelona, Spain

E-mail: francesca.ribas@upc.edu

E. Crews

WSP — Parsons Brinckerhoff, Southernhay Gardens, Exeter, EX1 1NT, UK

E-mail: Eddie.Crews@wspgroup.com 
9 U.K.). They consist of two bumps separated by embayments with a $350-450 \mathrm{~m}$ 10 spacing. We have analysed 36 shoreline surveys of $2 \mathrm{~km}$ length using the Dis11 crete Fourier Transformation (DFT), from 2005 to 2016, and seven topographic 12 surveys encompassing the intertidal zone, from 2010 to 2016. The data set shows 13 two clear formation events. In order to test the role of high-angle waves on the 14 KSSW formation, the 10-yr wave series is propagated from the wave buoy located 15 at $43 \mathrm{~m}$ depth up to a location in front of the undulations at $4 \mathrm{~m}$ depth using the SWAN wave model. The dominating SW waves arrive with a very high inci17 dence angle $\left(\sim 80^{\circ}\right)$ while the NE waves arrive almost shore normal. The ratio $18 R$, which measures the degree of dominance of high-angle waves with respect to 19 low-angle waves, correlates well with the shoreline DFT-magnitude values of the observed wavelength undulations. In particular, the highest $R$ values coincide with 21 the formation events. Finally, a linear stability model based on the one-line ap22 proximation is applied to the Dungeness profile and the 10-year propagated wave 23 series. It predicts accurately the formation moments, with positive growth rates in the correct order of magnitude for wavelengths similar to the observed ones.

25 All these results confirm that the shoreline undulations in Dungeness are selforganized and that the underlying formation mechanism is the high-angle wave instability. The two detected formation events provide a unique opportunity to 28 validate the existing morphodynamic models that include such instability.

29 Keywords Shoreline sand waves $\cdot$ self-organization $\cdot$ high-angle waves 
30 1 Introduction

40 Falqués, 2014a). They are associated to similar undulations in the bathymetric

41 contours beyond the surf zone and their typical wavelength on open ocean sandy

42 beaches is typically in the range $1-10 \mathrm{~km}$ (or more) so that they have been referred

43 to as km-scale shoreline sand waves (KSSW). However, undulations of this type

44 also show up in lower energy coasts with wavelengths of a few hundred meters

45 (Medellín et al, 2008; Ryabchuk et al, 2011).

46 Shoreline undulations at these large scales can be forced by offshore bathymet-

47 ric features or by geologic constraints but we here deal with those that are self-

48 organized. This means that they emerge from the internal dynamics of the coastal

49 system by positive feedbacks between hydrodynamics and morphology (Coco and

50 Murray, 2007). One of these feedback mechanisms is originated by the differential

51 topographic wave refraction along an undulating coastline (with the associated

52 undulating bathymetric contours) in case of oblique wave incidence. These dif-

53 ferences in wave refraction cause differences in wave crest stretching that induce 
54 alongshore gradients in wave energy hence in sediment transport rate, creating areas of deposition or erosion. If the deposition occurs at the prograding sections

6f the undulation and the erosion at the embayments, a positive feedback occurs. It turns out that this is the case for high-angle waves (angle between wave prop58 agation direction at the depth of closure and shore normal $\gtrsim 45^{\circ}$ ) so that this instability is known as high-angle wave instability (HAWI) (Ashton et al, 2001;

60 Falqués and Calvete, 2005). The potential for shorelines to develop high-angle wave instability has been amply confirmed by mathematical modelling during the 62 last two decades. These studies focus on the physics of the basic positive feedback 63 (Ashton et al, 2001; Falqués et al, 2017), the bathymetric and wave conditions 64 which are prone to the instability (Falqués and Calvete, 2005; Idier et al, 2017), 65 its characteristic length scale (van den Berg et al, 2014) and its finite amplitude 66 development (Ashton et al, 2001; Ashton and Murray, 2006a; van den Berg et al, 2012; Kaergaard and Fredsoe, 2013a). Also, the proportion of high-angle waves in the wave climate which is necessary to trigger HAWI has been investigated. The quite idealized model of Ashton et al (2001) predicts a 50\% while more realistic models require up to $80 \%$ of high-angle waves (van den Berg et al, 2012; Kaergaard 71 and Fredsoe, 2013a).

72 However, testing HAWI as the origin of KSSW in nature is more difficult. It 73 has been well documented that KSSW tend to occur along coasts where the wave 74 climate is dominated by high-angle waves. The cases of some elongate water bodies 75 (Ashton et al, 2009), Lake Erie (Davidson-Arnott and van Heyningen, 2003; Ashton 76 and Murray, 2006b) or the west coast of Africa (Kaergaard and Fredsoe, 2013b; 77 Idier and Falqués, 2014b) are quite clear. Other less conclusive examples include 78 the case of the west Danish coast (Kaergaard et al, 2012; Falqués et al, 2017), 
the Carolina capes (Ashton et al, 2001; Ashton and Murray, 2006b), the Dutch coast (Ruessink and Jeuken, 2002; Falqués, 2006) and the eastern gulf of Finland

${ }_{81}$ (Ryabchuk et al, 2011). However, all these cases concern already fully formed features while observations of the initiation (or the destruction) moments are very

3 scarce. An important reason is that such tests require detailed measurements of the bathymetry and the wave conditions at the moment of their formation from

85 a featureless morphology. To our knowledge, there is only one observational work focusing on the formation/destruction. Medellín et al (2009) identified periods of roughly two months were the shoreline undulations were visible at El Puntal Beach (Santander bay) and they spotted the formation and destruction moments. The linear stability analysis for the observed wave parameters was done and indeed there was some correlation between the largest values of the growth rate and the 
The wave climate at this coast is bimodal, with main wave directions from the south-west (SW) and from the north-east (NE). The dominant SW waves are very oblique with respect to the north-east flank while the NE waves are between shore normal and moderately oblique. According to the HAWI hypothesis the SW waves have the potential to trigger KSSW while the NE waves could inhibit the growth. Thus this coast is a potential site to test the HAWI hypothesis. The investigation of these undulations at Dungeness is relevant not only from a geomorphological point of view but also because they produce erosional hot spots in the embayments. Moreover, studying the formation of the shoreline undulations and the role of highangle waves can provide insight into the dynamics of the whole foreland.

The aims of the present contribution are: 1) to present a new KSSW site by characterizing the events of formation, and further development of the shoreline undulations at Dungeness and 2) to test the HAWI hypothesis for the formation of these KSSW by investigating the possible correlation between the KSSW events and both the propagated wave conditions and the output of a linear morphodynamic model. The observations are first presented and the shoreline waviness is quantified using the Discrete Fourier Transform (Section 2). Subsequently, the measured 10-year wave conditions are propagated from an available buoy (located at $43 \mathrm{~m}$ depth) up to $4 \mathrm{~m}$ depth in front of the features, using the SWAN model (Booij et al, 1999) (Section 3.1). Then, the dominance of high-angle waves over lowangle waves is correlated with the presence of shoreline sand waves (Section 3.2). Afterwards, a morphodynamic model based on linear stability analysis (Falqués and Calvete, 2005) is used to find out the initial growth rates of the relevant wavelengths using the propagated wave conditions as model input (Section 3.3). 


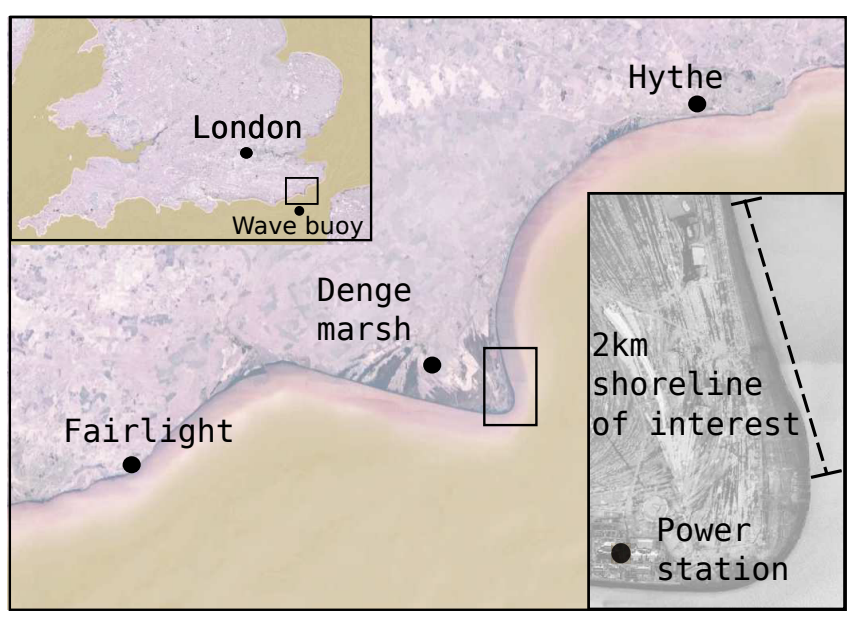

Fig. 1 Location map with a zoom in the particular area of interest. The satellite images are taken from Google Earth and correspond to September 2013. The North direction points upwards.

Finally, the results are discussed in Section 4 and the most important conclusions are listed in Section 5.

\section{Observations}

Dungeness is the largest cuspate foreland of the southern English shore (Figure 1) and, together with the adjacent areas, form a shingle system of 37 kilometres of coastline (from Winchelsea at the south-west to Hythe at the north-east). This shingle system forms a coastal barrier protecting several marshes (McGregor and Green, 1989). The foreland was already present back in the year 300-400 A.D., and it has been growing and migrating towards the north east since then (Long et al, 2006). Thereby, the south-west (north-east) flank shows an eroding (accreting)

139 long-term trend. The area studied in this contribution is the 2-km long coastline 


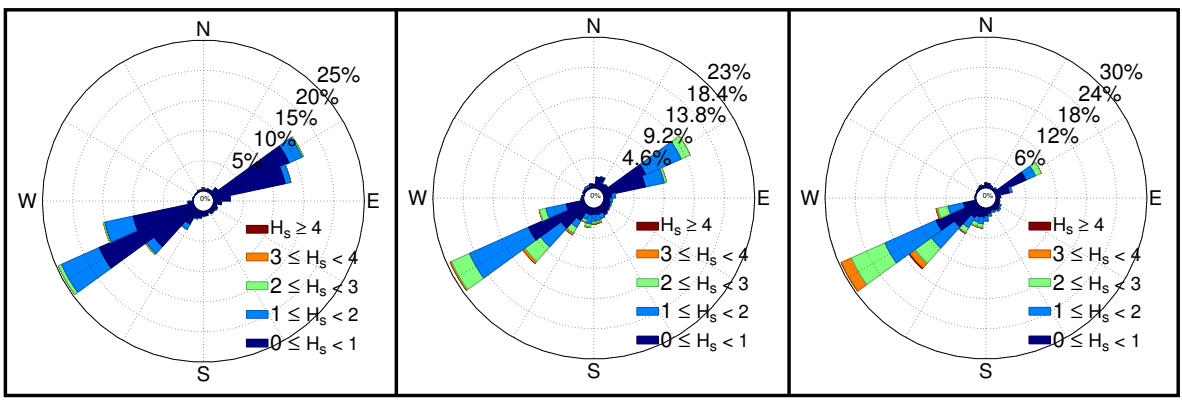

Fig. 2 Offshore wave roses for the periods of March 2005 - September 2005 (left), October 2005 - March 2006 (center), and February 2014 - July 2014.

at the north-east flank of the foreland (see Figure 1), which has an average shoreline orientation of $\sim 170^{\circ}$ with respect to north. The shingles in our area of interest, with a mean grain size varying between $10 \mathrm{~mm}$ and $20 \mathrm{~mm}$ (Dornbusch, 20032005), can be classified as gravel sediment. The beach foreshore in this area is steep, consistent with the large grain size, with a mean intertidal beach slope of 0.08. The slope is largest at the tip of the cape and decreases northward. The region is macrotidal with a mean tidal range of $6.7 \mathrm{~m}$ (Long et al, 2006). The waves arrive to Dungeness mainly from the SW and from the NE, the former being dominant. The averaged significant wave height $\left(\overline{H_{s}}\right)$ is $1.0 \mathrm{~m}$ and the corresponding peak period $\left(\overline{T_{p}}\right)$ is $5.5 \mathrm{~s}$. In the present work we focus on the potential role of waves and ignore the tidal forcing because the waves have been attributed to be the principal driver of littoral drift in this site (Lewis, 1932).

The offshore wave conditions during the study period are obtained from a wave buoy at $43 \mathrm{~m}$ depth located at the south of Dungeness Foreland, in front of Hastings. The wave climate is bimodal, with SW waves (high-angle waves at our area of interest) occurring during $65 \%$ of the time and NE waves (between low- and intermediate-angle waves at our area of interest) occurring during $35 \%$ 


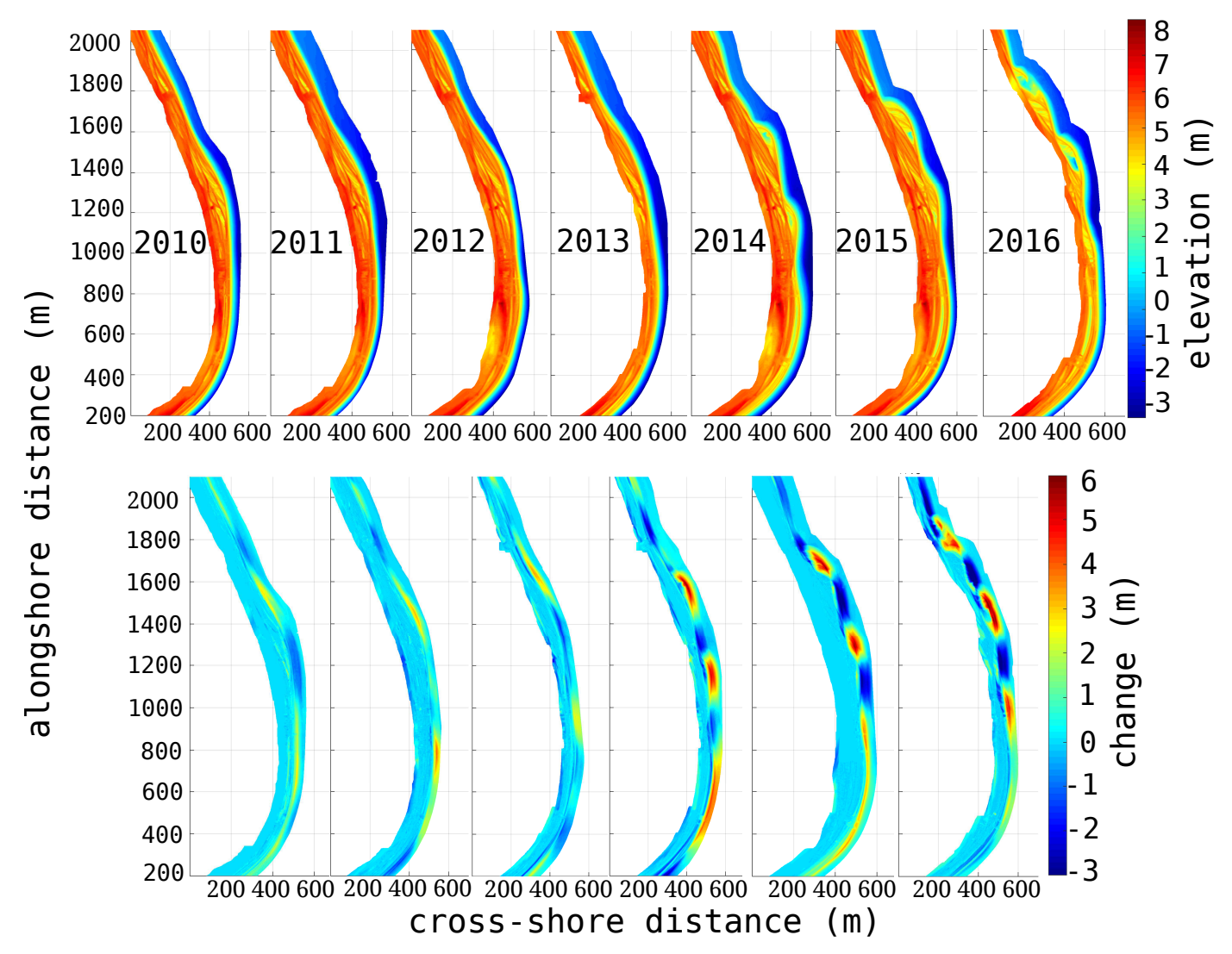

Fig. 3 Surface elevation plots (up) for the years 2010-2016 around July and the corresponding elevation change plots (down) between years. The North direction points upwards.

of the time. The SW waves are also more energetic, with an average significant wave height $\left(\overline{H_{s}}\right)$ of $1.1 \mathrm{~m}$ and an average peak period $\left(\overline{T_{p}}\right)$ of $5.7 \mathrm{~s}$, while the $\mathrm{NE}$ waves show $\overline{H_{s}}$ of $0.9 \mathrm{~m}$ and $\overline{T_{p}}$ of $4.9 \mathrm{~s}$. Figure 2 presents wave roses during different time intervals showing that the percentage of occurrence and intensity of 161 both types of incoming waves varies significantly during the study period. 
2.2 Qualitative description of the shoreline sand waves

A high-resolution topographic monitoring is being undertaken by the Canterbury Council as part of the South-east Strategic Regional Coastal Monitoring Program, providing one topographic survey every year around July from 2010 to 2016. The surveys are recorded using differential GPS randomly sampled with a spatial horizontal resolution of approximately $2-4 \mathrm{~m}$. They cover a vertical range from $+6 \mathrm{~m}$ to $-3 \mathrm{~m}$ with respect to the ordnance datum of Great Britain, encompassing the intertidal zone. Figure 3 shows the topographic maps and the bed level change plots, which have been generated using the open source topographical scatter data obtained from the Channel Coastal Observatory (U.K.).

Two striking shoreline undulations with a wavelength of about $450 \mathrm{~m}$ are clearly observed in the topographic survey of 2014 (Figure 3). These undulations persist during 2015 and 2016 while migrating about $350 \mathrm{~m}$ to the north. The undulations are observed across the whole intertidal zone. The bed-level-change-plot during the formation moment (2013-2014) display a clear pattern of erosion/accretion (red/blue in the lower plots of Figure 3). This erosion/accretion pattern translates to the north during 2014-2015 and 2015-2016 coherent with the growth and migration of the undulations. In contrast, for previous years the bed level change is weaker and the corresponding erosion/accretion patterns go back and forth without a net translation. The topographic plot of 2016 indicates that the northern crest (at $y \sim 1800 \mathrm{~m}$ ) starts to diffuse, as it can also be seen from the distortion in its accretion pattern. This is coherent with the fact that farther north no undulations appear (not shown here). 


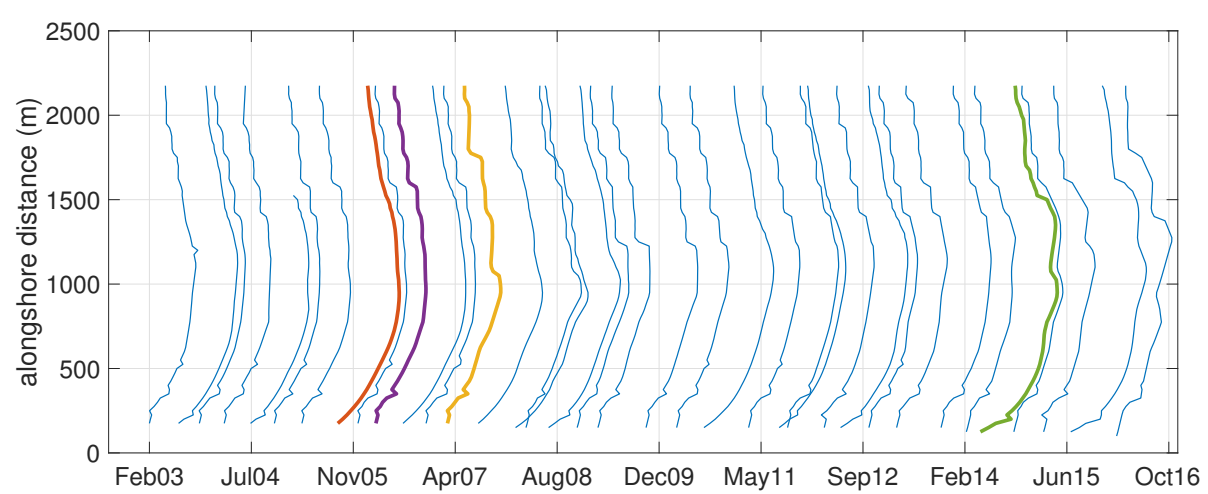

Fig. 4 Shorelines extracted from February 2003 until February 2016. The time is displayed in the $\mathrm{x}$-axis (the lower end of each shoreline indicates its survey time) but the shorelines have the same spatial scale in both axis. The thicker lines correspond to the four dates analysed in Figure 5 and discussed in the text.

Moreover, intertidal profile surveys are also performed by the Canterbury Council every spring, summer and autumn using differential GPS since 2003. The profiles have a cross-shore resolution of about $5 \mathrm{~m}$ (to some $z=-2 \mathrm{~m}$ ) and an alongshore spacing of about $60 \mathrm{~m}$. This second data set is also obtained from the Channel Coastal Observatory. The shorelines have been derived from the two available data sets by interpolating the position corresponding to $z=0$. In total, we have extracted 36 shorelines of 2 km length from February 2003 until February 2016.

Figure 4 displays the evolution of the shoreline in time, in which undulations of various wavelengths can be observed. In general, the shorelines can be classified visually in three types: straight (e.g., September 2005, red line), with small-scale undulations (around $200 \mathrm{~m}$ wavelength, e.g., March 2006, purple line), and with larger-scale undulations (around $400 \mathrm{~m}$ wavelength, e.g., February 2007, orange line, and July 2014, green line). The shoreline data confirm the presence of undu- 
lations of $\sim 450 \mathrm{~m}$ wavelength from July 2014 until February 2016. Moreover, in the shoreline of February 2007, undulations with a slightly smaller wavelength are also visible (of $\sim 350 \mathrm{~m}$ ). Finally, smaller-scale undulations with a wavelength of $\sim 200 \mathrm{~m}$ appear and disappear throughout the whole study period in many of the shorelines.

\subsection{Shoreline analysis}

The Discrete Fourier Transform (DFT) technique is used to quantify the shoreline undulations. The shorelines are first smoothed using a running average (with a window size of $500 \mathrm{~m}$ ) to obtain average shorelines. Then, the average shorelines are subtracted from the original ones obtaining the rectified shorelines, which show the characteristics of the undulations around an approximately constant straight line. Finally, the DFT of the rectified shorelines is computed. Figure 5 shows the DFT magnitude of the four shorelines shown with colours in Figure 4. The first one (September 2005) represents a shoreline with no clear dominant wavelength, the second one (March 2006) has a clear peak around $200 \mathrm{~m}$, the third one (February 2007) shows a dominant wavelength of about $350 \mathrm{~m}$ and the fourth one (July 2014) shows a dominant wavelength of about $450 \mathrm{~m}$.

In order to have a condensed and robust representation of the time evolution of the undulations, the DFT magnitude of the two wavelengths that best characterise the observed undulations (350 $\mathrm{m}$ and $450 \mathrm{~m}$ ) are extracted for each shoreline (upper panel of Figure 6). In particular, we compute the average of the DFT magnitude within a range of $\pm 30 \mathrm{~m}$ around each of the two wavelengths. From November 2006 until May 2007, there is a peak corresponding to the undulations at wavelengths of 

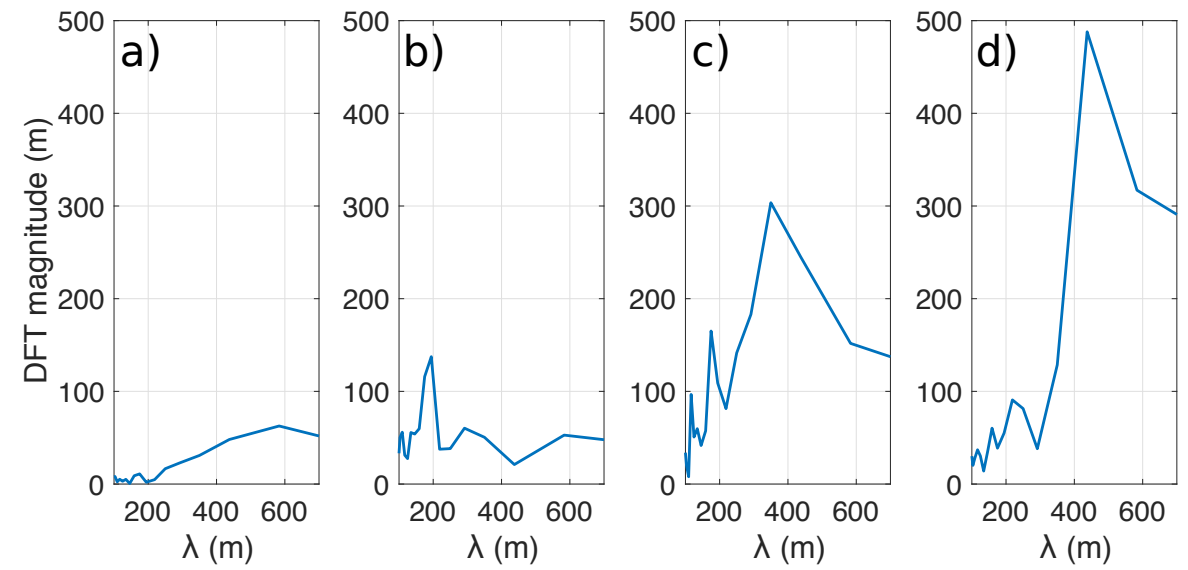

Fig. 5 Magnitude of the Discrete Fourier Transform of the rectified shorelines of September 2005 (a), March 2006 (b), February 2007 (c), and July 2014 (d).

$350 \mathrm{~m}$. These latter undulations decay gradually and they are no longer observed during spring-summer 2009. From July 2014 until the end of the study period a second (and the largest) peak is detected, corresponding to the undulations at wavelengths of $450 \mathrm{~m}$.

The DFT-magnitude of the $200 \mathrm{~m}$ wavelength has also been computed (not shown) and it displays a different behaviour from that of the larger wavelengths, with smaller values and a shorter term variability, apparently not correlated with any characteristic of the wave climate. Moreover, these smaller wavelengths are close to the alongshore resolution of the surveyed profiles $(60 \mathrm{~m})$ so that the alongshore spacing between cross-shore sections may be too large to properly resolve such scale. Given that the detection of such wavelengths is not completely reliable and that, in any case, they seem to be related to different physical processes (because they show a different behaviour), the rest of this study focuses on the larger-scale features. 
3 Modelling

\subsection{Wave transformation}

In order to investigate the relationship between the observed shoreline sand waves and the high-angle wave instability, the wave parameters at the depth of closure in front of the sand wave area are needed. Thereby, the 10-yr hourly wave parameters at the offshore buoy are propagated to this onshore location using the SWAN model. This is a third-generation wave model that represents the sea state in two dimensions by solving the spectral action balance equation. The details of the model are reported by Booij et al (1999) (version 41.10 is used here). Some physical processes that can be described with the SWAN model are ignored in the present simulations. In particular, we ignore the wind wave generation and the quadruplet and triad interactions. Instead, diffraction and dissipation by depthinduced breaking and bottom friction are accounted for.

The bathymetry is created by combining two surveys. The first one has a resolution of $0.5 \times 1.0 \mathrm{~km}$ (in the north and east directions respectively) and reaches depths of $50 \mathrm{~m}$. The second survey has a resolution of $\sim 2 \times 2 \mathrm{~m}$ and reaches $\sim 1.0 \mathrm{~km}$ offshore. For optimization purposes, the SWAN model is first applied to two coarse grids, one of $46 \times 45 \mathrm{~km}$ for SW waves (Figure 7 ) and another of $37 \times 65 \mathrm{~km}$ for NE waves (not shown). The cell size in these two coarse grids is $380 \times 380 \mathrm{~m}$. A nested grid of $2 \times 5 \mathrm{~km}$ is also used for both types of waves (Figure 8), which has a resolution of $8 \times 50 \mathrm{~m}$. A sensitivity analysis to the size of the grids and their resolution has shown that this configuration is optimal and provides an acceptable accuracy. The lateral and offshore boundaries are forced uniformly using a JONSWAP spectrum with the peak enhancement parameter default of 
3.3 and a directional distribution of 10 degrees (for each wave conditions). The directional distribution is chosen accordingly to the work done by Kaergaard and Fredsoe (2013b) in the context of HAWI.

After applying the SWAN model, the propagated 10-yr wave series is obtained by averaging the wave parameters along the $4 \mathrm{~m}$ contour depth in front of the area of interest (i.e., the 2 alongshore kilometres shown in Figure 1). Figure 9 shows the wave conditions at the buoy and at $4 \mathrm{~m}$ depth from October 2013 until June 2014, as an example. The SW waves experience strong refraction during their propagation towards the sand wave area, which causes a significant energy dispersion. This is translated into a significantly smaller $H_{s}$ in shallow waters in comparison with the buoy (Figures 7-9). In contrast, the $H_{s}$ of NE waves is kept relatively unchanged. Moreover, the waves with a very high incidence angle (with respect to the studied shoreline) do not necessarily have an effect on the study area as only waves with an angle smaller than $90^{\circ}$ contribute to alongshore sediment transport. For example, at $6 \mathrm{~m}$ depth only $23 \%$ of SW waves have a wave angle smaller than $90^{\circ}$, while this is true for $63 \%$ of SW waves at $4 \mathrm{~m}$ depth. This percentage increases for decreasing depths due to the wave transformation over the fan-shaped bathymetric contours (i.e., the bathymetric contours gradually diverge northwards, as can be seen in the left panel of Figure 8).

3.2 Correlation between shoreline sand wave presence and high-angle waves

There is some debate on the definition of high angle waves, i.e., on the precise value of the wave angle at the depth of closure, $\theta_{c}$, above which HAWI develops. Ashton et al (2001) gave the value of $\theta_{c}=42^{\circ}$. However, this theoretical prediction can 

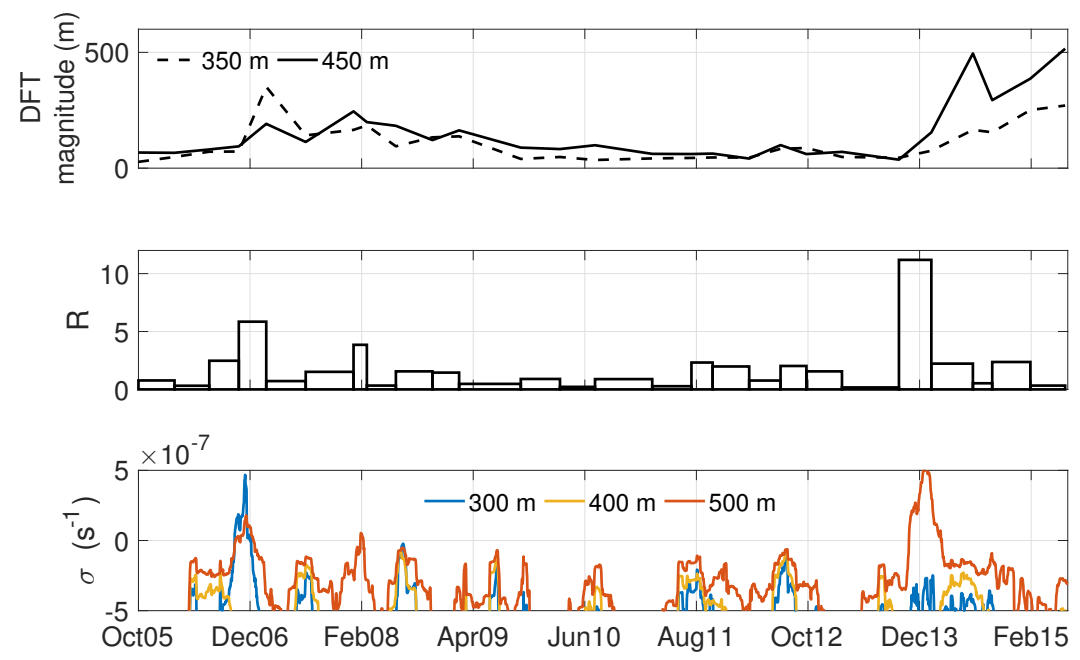

Fig. 6 DFT magnitude of the two wavelengths characterising the observed shoreline sand waves (upper panel), coefficient $R$ averaged during the time period between consecutive shoreline surveys (middle panel) and growth rate of the LSA model for three wavelengths (lower panel).

vary depending on the sediment transport formula (Ashton and Murray, 2006b), on the assumptions of the model (Falqués and Calvete, 2005; van den Berg et al, 2012; Kaergaard and Fredsoe, 2013a) and on the shape of the bathymetric undulations associated to the shoreline undulations (Idier et al, 2017). In this section we adopt the value $\theta_{c}=45^{\circ}$ for being representative of most of the predicted values.

To quantify the degree of dominance of destabilizing over stabilizing waves in the wave climate (i.e., high-angle waves, $|\theta|>45^{\circ}$, versus low-angle waves, $|\theta|<45^{\circ}$ ), we define the "strength" of the high-angle waves for each time survey, $t_{k}$, as

$$
E\left(t_{k}\right)_{>45^{\circ}}=\int_{45^{\circ}}^{89^{\circ}} d \theta \int_{t_{k-1}}^{t_{k}} H^{5 / 2} d t+\int_{-89^{\circ}}^{-45^{\circ}} d \theta \int_{t_{k-1}}^{t_{k}} H^{5 / 2} d t
$$



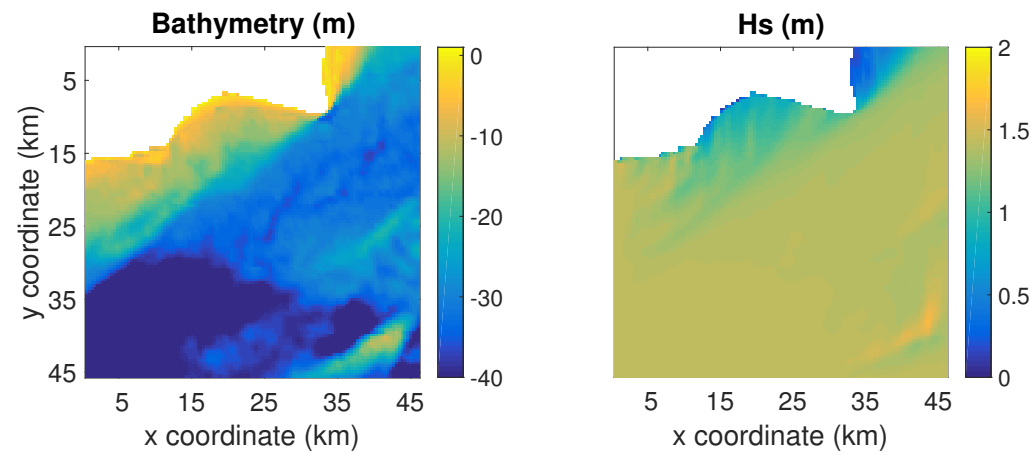

Fig. 7 Coarse grid bathymetry (left panel) and significant wave height (right panel) for the SW wave averaged conditions. The North direction points upwards.
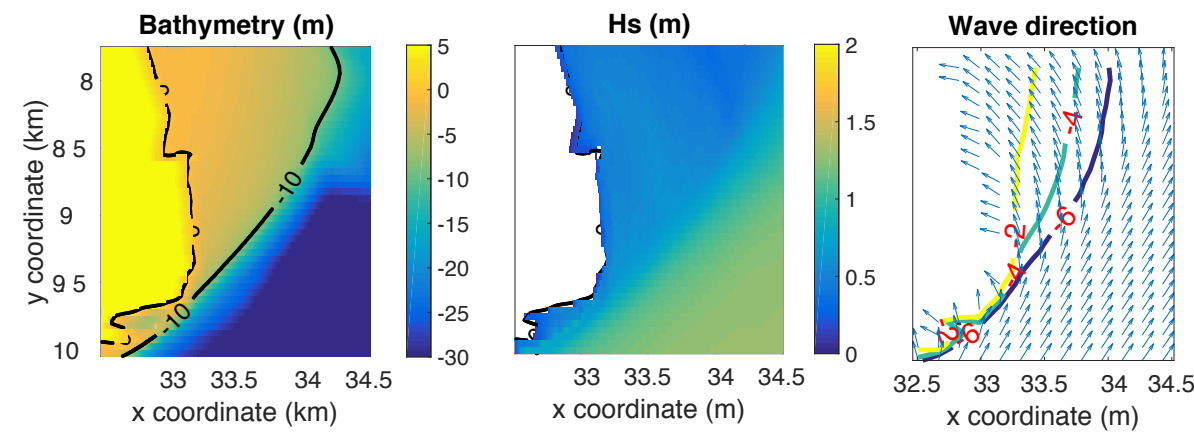

Fig. 8 Nested grid bathymetry (left panel). Propagated SW averaged conditions: significant wave height (central panel) and the normalised wave number vectors (right panel). The North direction points upwards. where $H$ and $\theta$ in these formulas are those computed at $4 \mathrm{~m}$ depth in front of the shoreline wave area. The $5 / 2$ power is introduced because, according to the widely used CERC formula (Komar, 1998), the total alongshore transport rate is proportional to $H_{b}^{5 / 2}$. Similarly, the "strength" of the low-angle waves is defined as

$$
E\left(t_{k}\right)_{<45^{\circ}}=\int_{-45^{\circ}}^{45^{\circ}} d \theta \int_{t_{k-1}}^{t_{k}} H^{5 / 2} d t
$$


We then define the wave-dominance ratio, $R$, as $R\left(t_{k}\right)=E\left(t_{k}\right)_{>45^{\circ}} / E\left(t_{k}\right)_{<45^{\circ}}$. The time intervals with $R>1$ correspond to a dominance of high-angle waves over low-angle waves. The stronger $R$, the stronger the relative influence of high-angle waves.

The middle panel of Figure 6 shows the time series of $R$, obtained during the time period between consecutive shoreline measurements, from October 2005 to November 2015. The coefficient $R$ is almost always above 1 and there are two main peaks of about $R=11$ and $R=6$. The peak of $R=6$ coincides with the formation event of sand waves around February 2007, as can be seen in the corresponding DFT magnitude peak for $\lambda=350 \mathrm{~m}$. Relative low values of $R$ during April 2009 to September 2013 are roughly consistent with small DFT magnitudes of the two analysed wavelengths. The largest peak in $R$ takes place around February 2014, clearly related with the formation event of 2014 that is visible as an increase in DFT magnitude for $\lambda=450 \mathrm{~m}$. Notice that the $R$ peaks and the DFT-magnitude peaks display a small time lag of 3-6 months. This is a logical result because on the one hand the surveys are available every 3-4 months and on the other hand the shoreline undulations can only be detected when they have reached a significant amplitude.

3.3 Linear stability analysis

\subsubsection{Dmorfo model}

To further investigate whether the observed shoreline sand waves could be attributed to the high-angle wave shoreline instability (HAWI) we perform a linear stability analysis (LSA) corresponding to the mean alongshore morphological char- 

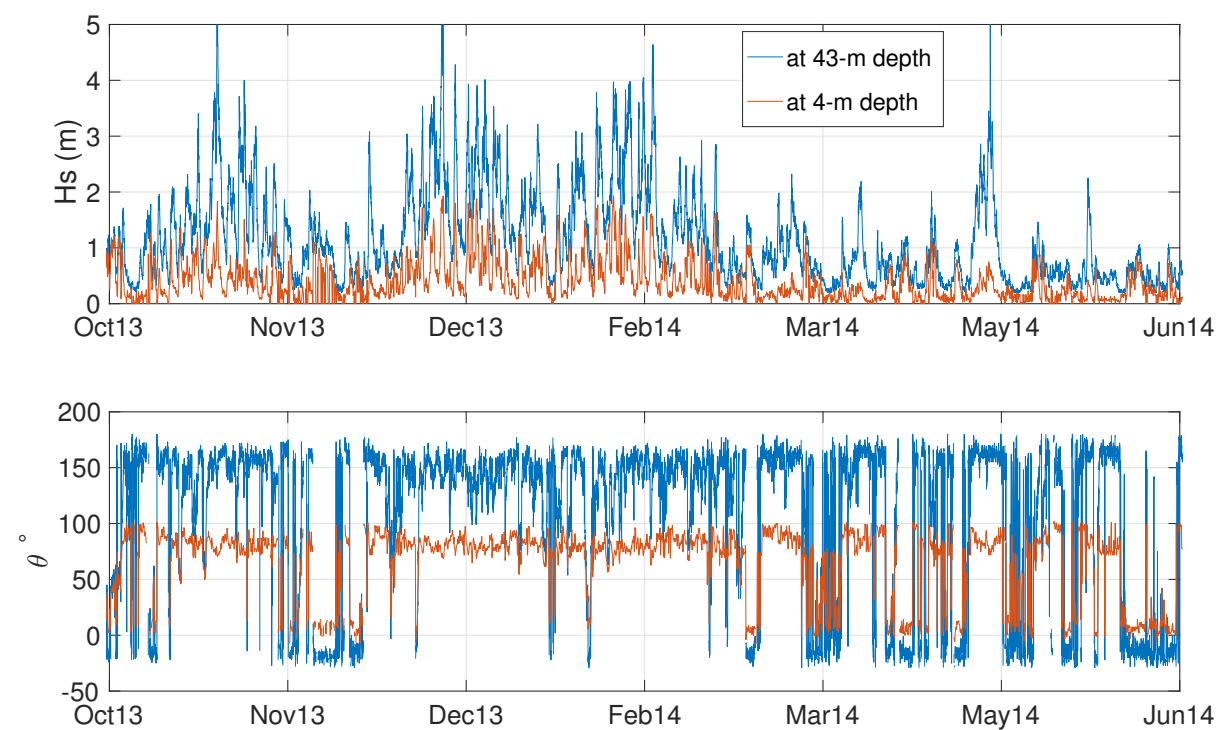

Fig. 9 Time series of the significant wave height (upper panel) and wave direction with respect to the shore normal of the studied shoreline stretch (lower panel) from October 2013 until June 2014. The blue line shows the offshore wave conditions recorded at the buoy (43 $\mathrm{m} \mathrm{depth)} \mathrm{and}$ the red line are the wave parameters at $4 \mathrm{~m}$ depth in front of the shoreline sand waves area.

acteristics of Dungeness and the propagated wave parameters. We use the 1Dmorfo model described by Falqués and Calvete (2005), whose basic concepts are as follows. A small-amplitude undulation is imposed on an initially rectilinear shoreline being defined as:

$$
y_{s}(x, t)=\frac{A}{2} \exp (\sigma t+i K x)+c . c .
$$

with $x, y$ being the Cartesian coordinates in the alongshore and cross-shore directions (respectively), $t$ the time, $A$ the amplitude, $K$ the alongshore wave number $(\lambda=2 \pi / K)$ and $\sigma=\sigma_{r}+i \sigma_{i}$ the complex growth rate. Regarding the unperturbed state, the main inputs of the model are the cross-shore equilibrium beach profile and the given wave parameters, i.e., significant wave height, peak period and angle 
at a certain depth (which in the present study will be the depth of closure, $D_{c}$ ). Regarding the perturbation, the main inputs are its alongshore wavelength, $\lambda$, its cross-shore shape and the depth of its offshore reach, $D_{c}$.

To compute the growth rate $(\sigma)$, Equation (3) is inserted into the one-line sediment conservation equation (Komar, 1998):

$$
\frac{\partial y_{s}}{\partial t}=-\frac{1}{\bar{D}} \frac{\partial Q}{\partial x}
$$

where $\bar{D}$ is a mean depth of the morphodynamic active zone and $Q$ is the total alongshore sediment transport rate. Here, $Q$ is computed with the CERC formula:

$$
Q=\mu H_{b}^{5 / 2} \sin 2 \alpha_{b}
$$

where $H_{b}$ and $\alpha_{b}$ are the wave height and wave angle with respect to the local shore normal at breaking and $\mu$ is an empirical constant. In the present contribution it is set to $\mu=0.15 \mathrm{~m}^{1 / 2} \mathrm{~s}^{-1}$. Computing the left hand side of Equation (4) is straightforward from Equation (3) but estimating the right hand side requires calculating the perturbed $H_{b}$ and $\alpha_{b}$. This is done by linearising (with respect to A) the equations describing refraction and shoaling over the perturbed bathymetry (the dispersion relation equation, the equation for wave number irrotationality and the wave energy conservation equation, not shown here) and computing $H_{b}$ and $\alpha_{b}$ numerically.

Regarding the model setup, the equilibrium cross-shore beach profile is extracted from combining the high-resolution intertidal topographic surveys (which extend to about $3 \mathrm{~m}$ depth) and the bathymetry extending 1-km offshore. The wave conditions at $D_{c}$ are obtained from those propagated with SWAN and two different types of simulations are performed (corresponding to the two following 
subsections): one type uses the full 10-yr wave series and the other type applies constant wave conditions. Regarding the perturbation, several values of $\lambda$ in the range of the observed ones are used. For the cross-shore shape of the perturbation we use a cross-shore shift of the profile as the shoreline moves onshore/offshore.

Given that the available high-resolution topographic measurements show that the shoreline sand waves extend across the whole measured domain, from $z=+4 \mathrm{~m}$ until $z=-3 \mathrm{~m}$ (Figure 3), we use a default depth of closure of $D_{c}=4 \mathrm{~m}$. The latter two choices are further motivated and discussed in Section 4.3.

\subsubsection{Wave series simulations}

The 10-yr wave series at $4 \mathrm{~m}$ depth (e.g., red lines in Figure 9) is used as input for the 1Dmorfo model. For each (hourly) record of the time series, $t_{j}$, and for a number of wavelengths, $\lambda$, the growth rate $\sigma\left(t_{j}\right)=\sigma_{r}\left(t_{j}\right)+i \sigma_{i}\left(t_{j}\right)$ for each wavelength is computed. This means that the amplification factor of a small amplitude sand wave with wavelength $\lambda$ from $t_{j}$ to $t_{j}+\Delta t$, where $\Delta t=1 \mathrm{~h}$ is $\exp \left(\sigma_{r}\left(t_{j}\right) \Delta t\right)$. Thus, when $\sigma_{r}(t)$ for a given $\lambda$ is positive, sand waves of this wavelength are expected to grow. On the contrary, when $\sigma_{r}(t)$ for a $\lambda$ is negative, such sand waves are expected to decay. The wave time series has a strong variability at hourly level while the morphology reacts much more slowly. For this reason instead of examining the raw $\sigma_{r}(t)$ time series we use a running average with a window of 90 days. The wave series simulation has been done for $\lambda=200 \mathrm{~m}$ to $\lambda=1000 \mathrm{~m}$ with a $20 \mathrm{~m}$ spacing. Notice that the 1Dmorfo model can only resolve length scales significantly larger than the surf zone width (which is about $30 \mathrm{~m}$ for the energetic periods).

The lower panel of Figure 6 shows the time series of such averaged $\sigma_{r}$ for $\lambda=$ 300,400 and $500 \mathrm{~m}$, which are relevant wavelengths according to the observations. 
It is seen that the growth rate for $\lambda=300 \mathrm{~m}$ is always negative, except during December 2006, preceding the sand wave formation event that is observed during the winter 2006-2007. In December 2006, the $\sigma_{r}$ corresponding to $500 \mathrm{~m}$ also has a positive value although smaller. This $\sigma_{r}$ corresponding to $\lambda=500$ is always negative except in December 2006 and in winter 2013-2014. During this second period it shows a remarkable peak, preceding the observed sand wave formation event of spring 2014. Thereby, the LSA model accurately predicts the observed shoreline sand wave formation moments, with the modelled wavelengths slightly underpredicting/overpredicting the observed ones in the first/second event. The characteristic growth time of the instability, $\sigma_{r}^{-1}$, is of 23 days in the peak of winter 2013-2014 (and slightly larger in the first event). This is in the correct order of magnitude in account of the observed reaction time of this morphological system.

It is found that the positive $\sigma_{r}$ periods occur when the $R$ ratio is large enough $(R>5)$, which is consistent with the HAWI theory. After the formation, although the modelled $\sigma_{r}$ switches from positive to negative values, the observed sand waves can persist or even keep on growing for a while. We must recall that the linear stability analysis is valid only for small amplitude sand waves and it is possible that, after the initial formation, non-linear interactions drive their dynamics. Finally, it is important to notice that the growth rate for $\lambda=400 \mathrm{~m}$ is always negative whilst one would expect positive $\sigma_{r}$ for this wavelength during the two formation events (since this $\lambda$ is close to the observed ones). The possible reasons for this behaviour are analysed in the next section.

Finally, the model predicts an averaged migration rate of $600 \mathrm{~m} / \mathrm{yr}$, for $\lambda=$ $500 \mathrm{~m}$, during the period between 2014-2016 (the period when undulations of this wavelength are observed to migrate, see Figure 3). The migration direction and 

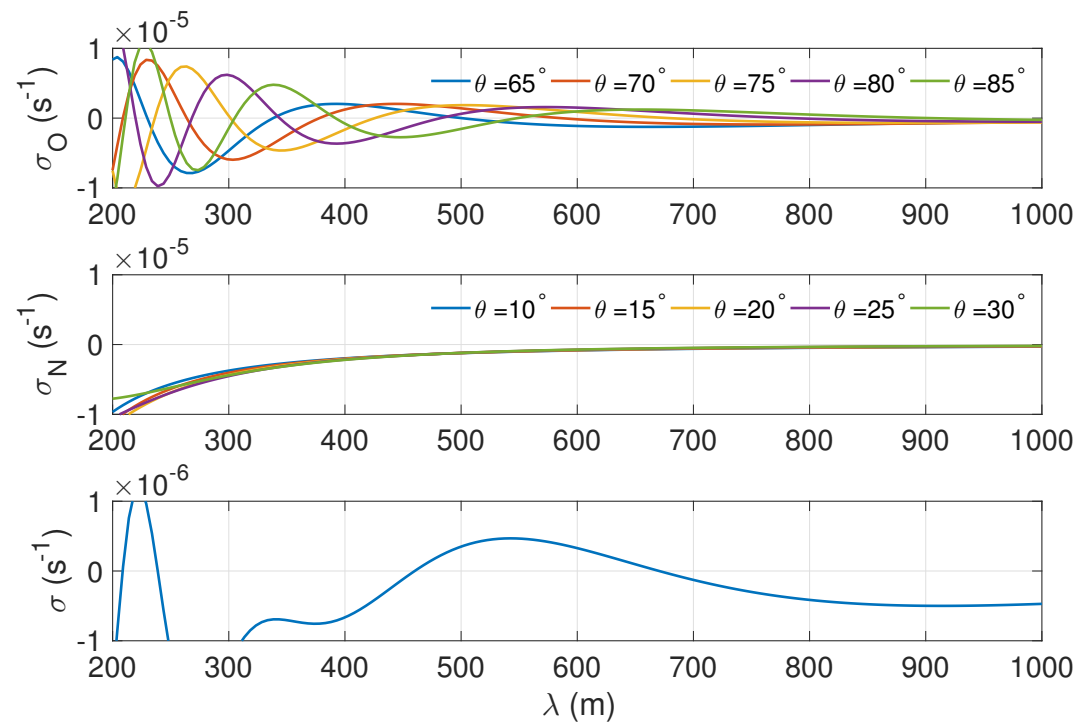

Fig. 10 Growth rate curves for different incident angles representing high-angle waves (upper panel) and low-angle waves (middle panel) during winter 2013-2014. Average growth rate curve (lower panel) using a weighting associated to the frequency of high and low-angle waves.

its order of magnitude agree with the observed ones (about $200 \mathrm{~m} / \mathrm{yr}$, see Section 2.2). The overprediction might be related to the fact that the model assumes perturbations of infinitesimal amplitude whereas the migration is observed for fully developed shoreline undulations. In other studies of coastal morphodynamic patterns, the migration rate in the non-linear regime is half of that obtained in the linear regime (Garnier et al, 2008).

\subsubsection{Constant waves simulations}

In order to understand the results of the wave series simulations, an analysis for constant (in time) wave parameters is very convenient. First of all, the average wave statistics of high-angle $\left(|\theta|>45^{\circ}\right)$ and low-angle $\left(|\theta|<45^{\circ}\right)$ waves are computed for the winter 2013-2014 period (prior to the second formation event). This gives 
$H_{s}=0.85 \mathrm{~m}, \theta=75^{\circ}$ and $T_{p}=6.8 \mathrm{~s}$ for high angles and $H_{s}=0.58 \mathrm{~m}, \theta=20^{\circ}$ and $T_{p}=5.1 \mathrm{~s}$ for low angles. During this period, high-angle waves occur $93 \%$ of the time and only $7 \%$ of the waves are low-angle (this can be appreciated in Figure $9)$. The 1 Dmorfo model is then run for high-angle and for low-angle waves with the corresponding values of $H_{s}$ and $T_{p}$. Five different angles are considered for each case: the average one and the latter $\pm 5^{\circ}$ and $\pm 10^{\circ}$. In this way, five growth rate curves $\left(\sigma_{r}-\lambda\right)$ for high-angle and five for low-angle waves are computed and shown in Figure 10.

As can be seen in that figure, the low-angle waves damp all the wavelengths, with a stronger damping for smaller wavelengths and smaller angles. In contrast, the high-angle waves produce positive $\sigma_{r}$ but, remarkably, each instability curve has three local maxima (in the range $\lambda>200 \mathrm{~m}$ ). The larger the angle, the larger the wavelengths of the maxima and the smaller the corresponding maximum $\sigma_{r}$ values. Typically, the instability curves for HAWI present a single maximum (Falqués and Calvete, 2005). However, as was found by van den Berg et al (2014), secondary maxima can sometimes occur. This happens for a marginal region in the parameter space, for very high wave angles, for some combinations of bathymetric profiles and wave periods, and for relatively short wavelengths ( $\lambda \sim 1 \mathrm{~km}$ or less), and it can be interpreted as follows. The damping of short wavelengths in HAWI is controlled by wave energy focusing/defocusing by the undulations (van den Berg et al, 2014). For relatively long wavelengths, in comparison with the offshore reach of the bathymetric perturbation, the focusing is always near the sand wave crests (i.e., the prograding section) and the defocusing near the embayments. This was also explained by Uguccioni et al (2006) as a result of each wave ray crossing only one of the shoals associated to the shoreline undulation. However, for relatively 
short wavelengths, large angle and small periods, each wave ray can cross several shoals. In this situation, the wave focusing can take place away from the crests and is highly sensitive to the wavelength, wave angle and bathymetry. As a result, the instability curve becomes quite complex for short wavelengths featuring several local maxima that look somewhat erratic (very sensitive to small changes in the angle and the bathymetry).

A way to filter out such strong sensitivity, in account of the inherent uncertainty sources coming from the parameters and the model, is to make an average of the different growth rate curves with a weighting associated to the frequency of high and low-angle waves. The corresponding averaged curve shows a local positive maximum at $\lambda \approx 540 \mathrm{~m}$ and another at $\lambda \approx 220 \mathrm{~m}$ (lower panel of Figure 10 ). Since the $220 \mathrm{~m}$ wavelength peak is in the lower limit of the length scales that can be resolved by the 1 Dmorfo model (given the surf zone width in this case) this averaging lends support to the robustness of $\lambda \approx 500 \mathrm{~m}$ as an output of the LSA for the time series of wave parameters. This is also in good agreement with the $450 \mathrm{~m}$ wavelength of the formation event in 2014. Rather, the wavelengths below $500 \mathrm{~m}$ must be taken with care and this explains why the LSA can predict growth for $\lambda=300 \mathrm{~m}$ and decay for $\lambda=400 \mathrm{~m}$ during the 2006-2007 event, where the observed wavelength is $\lambda \approx 350 \mathrm{~m}$.

\section{Discussion}

4.1 Role of HAWI on Dungeness shoreline undulations

Our hypothesis is that the shoreline undulations observed in Dungeness with wavelengths of about $350 \mathrm{~m}$ and $450 \mathrm{~m}$ can be classified as self-organized km- 


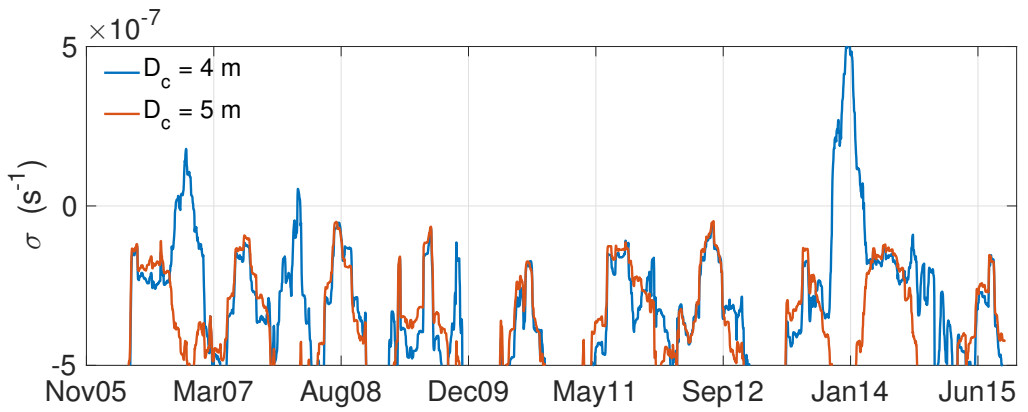

Fig. 11 Growth rate sensitivity of different wavelengths to the depth of closure.

scale shoreline sand waves (KSSW). However, these undulations could be related to other phenomena. Indeed, although beach cusps are quite common on gravel beaches their wavelength is at least one order of magnitude smaller than the observed one, discarding that the Dungeness undulations correspond to beach cusps. Instead, $350-450 \mathrm{~m}$ could be a very plausible wavelength for megacusps linked to rhythmic surf zone bars. However, rhythmic surf zone bars have never been observed on macrotidal gravel beaches (van Enckevort et al, 2004) and they do not show up in any of the available surveys of Dungeness. This is consistent with the fact that this beach is nearly reflective $(\Omega \sim 1.2$, where $\Omega$ is the dimensionless fall velocity parameter in Wright and Short, 1984). Therefore, we can also discard that the shoreline undulations are associated to rhythmic bars. The possibility that the shoreline sand waves could be forced rather than self-organized can also be discarded. Offshore Dungeness, there are sand banks (which can be observed in Figure 7) and the SWAN computations indeed show that they influence wave refraction and can focus wave energy. However, sensitivity analysis to the presence 43 of such offshore banks made with the SWAN model prove that the influence of the 474 sand banks does not reach the sand wave area. Another potential hydrodynamic 45 template forcing that could drive the shoreline undulations is wave diffraction, 
which can generate patterns in the wave energy field, which in turn could lead to associated patterns in the shoreline morphology. Indeed, the configuration of the Dungeness Cuspate Foreland causes diffraction of the SW waves around its tip. However, the SWAN model has been run including and neglecting wave diffraction. The simulations showed that this process just causes a slight decrease in wave energy without inducing alongshore rhythmic wave patterns.

The observations also confirm that the KSSW are a result of the high-angle wave instability (HAWI) because i) a clear correlation between its formation period and the occurrence of high-angle waves is found and ii) the results of the 1Dmorfo model, which includes such instability, are coherent with the observations (Figure 6). Also, it can be seen that the larger shoreline undulations $(\lambda=350-450 \mathrm{~m})$ appear when the high-angle wave energy is at least five times larger than the low-angle wave energy $(R>5)$. Several authors (Ashton and Murray, 2006b; van den Berg et al, 2012; Kaergaard and Fredsoe, 2013a) studied numerically the proportion of high-angle waves, $U$, required to de-stabilize the shoreline. This was done by forcing an idealized bathymetry with two wave conditions: $\theta=60^{\circ}$ or $\theta=30^{\circ}$ (having the same $H_{s}$ and $T$ ). The limit found ranged from $U \approx 0.5$ up to $U \approx 0.8$. In our approach, the proportion of high-angle waves, $U$, can be related with $R$ as $U=R /(1+R)$. Thus a threshold of $R \approx 5$ implies $U \approx 0.83$ which differs from the threshold of $U \approx 0.5$ predicted by Ashton and Murray (2006b) but is consistent with the threshold $U \approx 0.8$ found by the more realistic models of van den Berg et al (2012), and Kaergaard and Fredsoe (2013a).

Figure 6 also shows that the DFT-magnitude of the $350 \mathrm{~m}$ and $450 \mathrm{~m}$ wavelengths is maintained (or it even continues to increase) despite the $R$ values decreasing below the threshold (and the 1Dmorfo model hence predicting negative 
growth rates). It seems that once the sand waves have been formed, $R$ values above 2 would favour their maintenance and growth even if they are below the $R$ threshold. As discussed in Section 3.3.2, this behaviour cannot be reproduced by a linear model because non-linear effects play an important role in the finite-amplitude behaviour. Moreover, the morphological response do not only depend on the wave forcing but also on the previous morphological state (as has been recognized for different types of rhythmic features, see Calvete et al, 2007).

As mentioned in Section 2.2, the shoreline sand waves are restricted to the area close to the Dungeness tip, i.e., no undulations appear further north. Actually, no more than 3 crests can be observed at the same time. Also, during the migration experienced by the undulations in 2015-2016, the crest further north exhibits a distorted accretion/erosion pattern (it starts to diffuse) while the southern crests exhibit a consistent accretion/erosion pattern. There are two factors favouring this behaviour. First, the beach profiles have a milder slope to the north and according to HAWI theory milder slopes tend to diminish growth rates (Falqués and Calvete, 2005). Second, the SW waves have to travel larger distances further north, experiencing more refraction and more energy loss (Figure 7), while NE waves have approximately the same energy along the whole north-east flank of Dungeness. Therefore, the wave energy leading to a stable coastline (NE) is alongshore constant while the wave energy favouring the formation of the KSSW (SW) decays gradually to the north. The combination of the alongshore decrease of the SW energy and in beach profile would explain why the sand waves develop only close to the tip of the foreland. 

546 be desirable to study the role of tides. those of the observed undulations at Dungeness.

4.2 Role of tides on Dungeness shoreline undulations

This study has been based on the effect of the alongshore wave-driven transport while the possible morphodynamic effect of the tides (both the induced currents and sea-level variations) has been ignored. It is well known that the coupling of tidal waves and the sea bed morphology in the continental shelf can originate the formation of sand waves and sand ridges with wavelengths from hundreds of meters to kilometres, respectively (Blondeaux, 2001). Regarding the coastal zone, a tidal wave propagating along an undulating shoreline can create vortices in the horizontal residual circulation that can feedback positively into the undulations (Zimmerman, 1981; van der Vegt et al, 2007). However, the alongshore characteristic length scales of the corresponding positive feedback are typically larger than

Besides producing currents, the tides vary the water level and therefore the shoreline location. This is important because the linking of the shoreline undulations with the depth contours is accomplished by the cross-shore exchange of sediment. On a microtidal coast this is only done by storm waves but on a macrotidal coast the cross-shore sediment exchange can be enhanced by the cross-shore translation of the surf zone during the tidal oscillation. The model used in the present work does not take explicitly into account variations in the sea level but the tidal effect of enhancing the cross-shore sediment exchange is considered implicitly by increasing the depth of closure (see also next section). In any case, a modelling study including sea level variations and both wave- and tide-driven currents would 
4.3 Justification of the setup chosen in the 1Dmorfo model

Taking into account the bathymetric perturbation associated to the shoreline undulations is essential for the feedback between waves and morphology leading to HAWI. However, as the 1Dmorfo model is based on the one-line approximation, the link between shoreline undulations and bathymetric undulations must be prescribed. Available one-line models (e.g., Genesis, Unibest-CL) make this link by assuming a cross-shore shift of the profile following the perturbed shoreline. Applying this bathymetric perturbation, called $P 1$, the perturbed shoreline amplitude is the same as the cross-shore amplitude of any depth contour. Another plausible link is based on assuming a linear decay of the bed level perturbation. For this bathymetric perturbation, called $P 2$, the cross-shore amplitude of the depth contours beyond the surf zone can be larger than the amplitude of the perturbed shoreline (for certain profiles). The influence of this choice in the formation of KSSW has been investigated thoroughly by Idier et al (2017). It was found that low-angle waves can be de-stabilizing only for the perturbation $P 2$. It is unknown how frequent this occurs in nature, but it seems that it can happen at least in one case (Falqués et al, 2017). We have applied the 1Dmorfo model assuming both $P 1$ and $P 2$ because the bathymetric perturbation in the field can not be inferred from the available data. The growth rates using the perturbation $P 2$ (not shown) are positive for low-angle waves and negative for high-angle waves, for wavelengths in the order of the observed undulations. In contrast, the growth rates using the perturbation $P 1$ are negative for low-angle waves and positive for high-angle waves

(Figure 6). Since the observed formation events of sand waves are correlated with 
high-angle waves, we conclude that only the perturbation $P 1$ adequately represents the physics of the initial instability mechanism in this site.

Based on the fact that the observed KSSW extend up to $3 \mathrm{~m}$ depth, a depthof-closure value of $4 \mathrm{~m}$ is chosen in Section 3.3.1. In our study area, there are no available measurements of the $D_{c}$ derived from cross-shore profiles dynamics. A relatively close site with these type of measurements is the south of the Dutch coast, which is subject to more energetic waves. Hinton and Nicholls (1998) reported $D_{c}=5 \mathrm{~m}$. Also, the well-known Hallermeier formula (Hallermeier, 1981) can be used to provide an estimate (see, e.g., Falqués et al, 2017). For the case of Dungeness, the extremal wave height from the 10 -yr propagated series is $H_{e} \approx 1.3 \mathrm{~m}$, with a wave period $T_{p} \approx 5.2 \mathrm{~s}$, which gives $D_{c} \approx 2.5 \mathrm{~m}$. This closure depth is smaller than the depth at which the undulations are observed. Besides, the $D_{c}$ is overshadowed by the local tidal range of $6.7 \mathrm{~m}$. As discussed in Section 4.2, on a macrotidal coast $D_{c}$ can be larger compared with a microtidal coast with the same wave conditions. Therefore, the chosen closure depth of $4 \mathrm{~m}$ is reasonable. In order to check the sensitivity to the value of $D_{c}$, larger depths of closure have also been used in which case no growth is predicted to occur. As an example, Figure 11 shows that if $D_{c}=5 \mathrm{~m}$ only negative growth rates are obtained for $\lambda=500 \mathrm{~m}$. The reason for this behaviour is that the 1 Dmorfo wave propagation does not represent well the real propagation at this site. Our linear morphodynamic model assumes alongshore-uniform unperturbed depth contours parallel to the shoreline, while the contours at the north-east flank of the Dungeness foreland show a fan shape (i.e., the bathymetric contours gradually diverge northwards, as can be seen in Figure 8). Then, if a depth of closure of $6 \mathrm{~m}$ is taken, $77 \%$ of the $\mathrm{SW}$ incoming waves have an angle larger than $90^{\circ}$ at that depth and the model ignores the 
morphodynamic effect of these waves. Instead, at $4 \mathrm{~m}$ depth only $37 \%$ of $\mathrm{SW}$ waves can not be properly represented by the model.

\section{Conclusions}

The formation of km-scale shoreline sand waves (KSSW) with alongshore wavelengths of $350-450 \mathrm{~m}$ has been observed along the north-east flank of Dungeness foreland (U.K.), close to the tip. Two clear formation moments have been detected during the study period (February 2003 - February 2016), one on February 2007 with a wavelength of $350 \mathrm{~m}$ and the second one on July 2014 with a wavelength of $450 \mathrm{~m}$. A gradual decay of the 2007 shoreline undulations is observed and they are no longer visible on autumn 2009. The undulations formed at the second event persist at least until February 2016 (with some decay) and migrate northward at a mean rate of about $200 \mathrm{~m} / \mathrm{yr}$.

The role of the high-angle wave instability (HAWI) on the formation and dynamics of the shoreline undulations has been examined. A ratio quantifying the degree of dominance of high-angle waves over low-angle waves, $R$, has been computed at $4 \mathrm{~m}$ depth and a good correlation between high $R$ values and the formation of the shoreline sand waves has been found. In particular, the undulations occur when $R>5$ implying that an $80 \%$ of high-angle waves is needed to trigger their formation, in agreement with previous HAWI studies. We thus conclude that HAWI is the primary cause of the shoreline sand wave formation in Dungeness.

A linear stability analysis has also been performed using a morphodynamic model based on the one-line approximation that can describe HAWI. The model predicts positive growth rates previous to the two observed formation moments for 
wavelengths similar to the observed ones. It is also found that a bathymetric perturbation corresponding to a cross-shore profile shift is required to reproduce the growth of sand waves with the observed characteristics. Moreover, the morphological response occurs at time scales of the order of the observed ones (characteristic growth time of about one month and migration rates of hundreds of meters per year) and it is not only related to the wave forcing but also to the preceding bathymetric configuration. Finally, the applied linear model has been able to represent the initial formation of the undulations but it fails to reproduce the dynamics of the finite-amplitude features. A non-linear model is needed to reproduce the mediumterm and long-term evolution of the observed shoreline undulations. Indeed, the two events with KSSW formation and further evolution detected at Dungeness represent a unique opportunity to validate such models.

\footnotetext{
Acknowledgements This research is part of the Spanish Government project CTM201566225-C2-1-P (MINECO/FEDER). The first author was funded by the Mexican Government (CONACyT, grant number 217754). The topography data was undertaken by Canterbury Council as part of Southeast Strategic Regional Coastal Monitoring Program. The wave data was acquired from the UK wave buoy (WaveNet). delivered by the Centre for Environment Fisheries and Aquaculture Science (https://www.cefas.co.uk/cefas-data-hub/wavenet/). We would like to thank the Coastal Channel Observatory for providing the platform from which the topographical data was obtained. The wave data was acquired from the UK wave buoy (WaveNet) delivered by the Centre for Environment Fisheries and Aquaculture Science (https://www.cefas.co.uk/cefas-data-hub/wavenet/). Special thanks to Mike Walkden for his technical input and support.
} 
References

Ashton A, Murray AB (2006a) High-angle wave instability and emergent shoreline shapes: 1. Modeling of sand waves, flying spits, and capes. JGeophysRes 111:F04,011,doi:10.1029/2005JF000,422

Ashton A, Murray AB (2006b) High-angle wave instability and emergent shoreline shapes: 2. Wave climate analysis and comparisons to nature. JGeophysRes 111:F04,012,doi:10.1029/2005JF000,423

Ashton A, Murray AB, Arnault O (2001) Formation of coastline features by largescale instabilities induced by high-angle waves. Nature 414:296-300

Ashton AD, Murray AB, Littlewood R, Lewis DA, Hong P (2009) Fetch-limited self-organization of elongate water bodies. Geology 37:187-190

Blondeaux P (2001) Mechanics of coastal forms. Ann Rev Fluid Mech 33:339-370

Booij N, Ris RC, Holthuijsen LH (1999) A third-generation wave model for coastal regions: 1. Model description and validation. J Geophys Res 104(C4):7649-7666 Calvete D, Coco G, Falqués A, Dodd N (2007) (un)predictability in rip channel systems. Geophys Res Lett 34(L05605), doi:10.1029/2006GL028162

Coco G, Murray AB (2007) Patterns in the sand: From forcing templates to selforganization. Geomorphology 91(271-290)

Davidson-Arnott RGD, van Heyningen A (2003) Migration and sedimentology of longshore sandwaves, Long Point, Lake Erie, Canada. Sedimentology 50:11231137

Dornbusch U (2003-2005) BAR Phase I, Beach Material Properties . Tech. rep., University of Sussex 
Falqués A (2006) Wave driven alongshore sediment transport and stability of the Dutch coastline. Coastal Eng 53:243-254

Falqués A, Calvete D (2005) Large scale dynamics of sandy coastlines. Diffusivity and instability. J Geophys Res 110(C03007), doi:10.1029/2004JC002587

Falqués A, Ribas F, Idier D, Arriaga J (2017) Formation mechanisms for selforganized km-scale shoreline sand waves. J Geophys Res Earth Surf 122, 10.1002/2016JF003964

Garnier R, Calvete D, Falqués A, Dodd N (2008) Modelling the formation and the long-term behavior of rip channel systems from the deformation of a longshore bar. J Geophys Res 113(C07053), doi:10.1029/2007JC004632

Hallermeier L (1981) A profile zonation for seasonal sand beaches from wave climate. Coastal Eng 4(3):253-277

Hinton C, Nicholls RJ (1998) Spatial and temporal behaviour of depth of closure along the Holland coast. In: ASCE (ed) Coastal Eng. 1998, pp 2913-2925

Idier D, Falqués A (2014a) How kilometric sandy shoreline undulations correlate with wave and morphology characteristics: preliminary analysis on the Atlantic Coast of Africa. Advances in Geosciences 39:5560, doi:10.5194/adgeo-39-55-2014 Idier D, Falqués A (2014b) How kilometric sandy shoreline undulations correlate with wave and morphology characteristics: preliminary analysis on the Atlantic coast of Africa. Advances in Geosciences 39:55-60, doi:10.5194/adgeo-39$55-2014$

Idier D, Falqués A, Rohmer J, Arriaga J (2017) Self-organized kilometre-scale shoreline sandwave generation: sensitivity to model and physical parameters. J Geophys Res 122, doi:10.1002/2017JF004197 
Kaergaard K, Fredsoe J (2013a) Numerical modeling of shoreline undulations part

1: Constant wave climate. Coastal Eng 75:64-76

Kaergaard K, Fredsoe J (2013b) Numerical modeling of shoreline undulations part 2: Varying wave climate and comparison with observations. Coastal Eng 75:7790

Kaergaard K, Fredsoe J, Knudsen SB (2012) Coastline undulations on the West Coast of Denmark: Offshore extent, relation to breaker bars and transported sediment volume. Coastal Eng 60:109-122

Komar PD (1998) Beach Processes and Sedimentation, 2nd edn. Prentice Hall, Englewood Cliffs, N.J.

Lewis WV (1932) The Formation of Dungeness Foreland. Geographical Journal $80(4): 309-324$

Long AJ, Waller MP, Plater AJ (2006) Coastal resilience and late Holocene tidal inlet history: The evolution of Dungeness Foreland and the Romney Marsh depositional complex (U.K.). Geomorphology 82(3-4):309-330, DOI 10.1016/j.geomorph.2006.05.010

McGregor DFM, Green CP (1989) Geomorphology in conservation assessmentThe dungeness shingle system. Ocean and Shoreline Management 12(2):107-124, DOI 10.1016/0951-8312(89)90049-0

Medellín G, Medina R, Falqués A, González M (2008) Coastline sand waves on a low-energy beach at 'El Puntal' spit, Spain. Mar Geol 250:143-156

Medellín G, Falqués A, Medina R, González M (2009) Sand waves on a lowenergy beach at 'El Puntal' spit, Spain: Linear Stability Analysis. J Geophys Res 114(C03022), doi:10.1029/2007JC004426 
Ribas F, Falqués A, de Swart HE, Dodd N, Garnier R, Calvete D (2015) Understanding coastal morphodynamic patterns from depth-averaged sediment concentration. Rev Geophys 53, doi:10.1002/2014RG000457

Ruessink BG, Jeuken MCJL (2002) Dunefoot dynamics along the dutch coast. Earth Surf Process Landforms 27:1043-1056

Ryabchuk D, Leont'yev I, Sergeev A, Nesterova E, Sukhacheva L, Zhamoida V (2011) The morphology of sand spits and the genesis of longshore sand waves on the coast of the eastern Gulf of Finland. Baltica 24(1):13-24

Uguccioni L, Deigaard R, Fredsoe J (2006) Instability of a coastline with very oblique wave incidence. In: Coastal Eng. 2006, World Scientific, pp 3542-3553 van den Berg N, Falqués A, Ribas F (2012) Modelling large scale shoreline sand waves under oblique wave incidence. J Geophys Res 117(F03019), doi:10.1029/2011JF002177

van den Berg N, Falqués A, Ribas F, Caballeria M (2014) On the wavelength of self-organized shoreline sand waves. J Geophys Res Earth Surf 119:665-681, doi:10.1002/2013JF002751

van Enckevort IMJ, Ruessink BG, Coco G, Suzuki K, Turner IL, Plant NG, Holman RA (2004) Observations of nearshore crescentic sandbars. J Geophys Res 109(C06028), doi:10.1029/2003JC002214

van der Vegt M, Schuttelaars HM, de Swart HE (2007) Modeling the formation of undulations of the coastline: The role of tides. Continental Shelf Research 27(15):2014-2031, DOI 10.1016/j.csr.2007.04.006

Verhagen HJ (1989) Sand waves along the dutch coast. Coastal Eng 13:129-147

Wright LD, Short AD (1984) Morphodynamic variability of surf zones and beaches: A synthesis. Mar Geol 56:93-118 
737 Zimmerman JTF (1981) Dynamics, diffusion and geomorphological significance of tidal residual eddies. Nature 290:549-555 